\title{
A RENDA BÁSICA ESTARÁ NO ESTADO PÓS-COVID-19?
}

\author{
A BASIC INCOME WILL BE IN THE STATE PÓS-COVID-19?
}

\author{
Gabriel Vieira de Souza ${ }^{\mathrm{I}}$ \\ Fernando Gustavo Knoerr ${ }^{\mathrm{II}}$ (i)
}

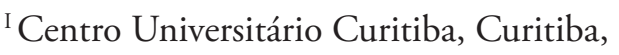
PR, Brasil. Mestrando em Direito Empresarial e Cidadania. E-mail: gabrielsouza15000@gmail.com

${ }^{\text {II }}$ Centro Universitário Curitiba, Curitiba, PR, Brasil. Pós-Doutor em Direitos Humanos.
}

Resumo: O Estado pode ser considerado a mais extraordinária e duradoura ficção político-jurídica criada pela humanidade. No mundo de hoje é raro algum ser humano não viver sob sua égide. Ocorre que, como acontece desde os primórdios da organização das sociedades políticas, a exemplo da Polis grega e da Civita romana, o Estado vive em constante transformação, oriunda da busca permanente de estabilização do contrato social. Tais transformaçóes aceleram-se consideravelmente em tempos de crise, como já registrou a história nas duas Grandes Guerras do século XX, no crash da Bolsa de Nova Iorque de 1929 e como hoje é o caso da pandemia da COVID-19. Nesses períodos, o Estado vê-se premido a proceder intervençóes agressivas na economia, buscando sustentar subsidiariamente a atividade econômica, momentaneamente paralisada devido às medidas de contenção do vírus. Assim, propostas que no passado recente não eram sequer consideradas, hoje estão encontrando espaço para saírem do papel. Uma delas é a referente à Renda Básica. As origens dessa ideia, bem como seus princípios norteadores, são elementos fundamentais para que se possa compreendê-la. O Brasil, em que pese nunca a tenha posto em prática, desde 2004 conta com lei que disciplina o tema. No atual momento de crise, o Estado brasileiro aprovou a Renda Básica Emergencial, que pretende remunerar aqueles indivíduos que tiveram sua renda interrompida pelas medidas de contenção à pandemia e, portanto, tem praticado uma ação muito próxima a da Renda Básica clássica. Qual Estado emergirá no pós-crise? Terá a Renda Básica espaço nesse novo contrato social? Essas são questôes a serem respondidas neste trabalho. $\mathrm{O}$ que se pode concluir é que, após esse período revolucionário para a ação humana, com as profundas transformaçóes ocorridas no capitalismo nesse século, e talvez com um novo arranjo do panorama econômico mundial, haverá a necessidade de atualização da forma e dos meios de relacionamento do Poder Público com a sociedade civil e com a economia, abrindo espaço para a consolidação da política de Renda Básica como uma ação permanente do Estado.

Palavras-chave: Estado. Renda Básica. COVID-19. Renda Básica Emergencial.
Recebido em: 16.01 .2020

Aceito em: 21.07.2020 


\begin{abstract}
The State must be considered the most extraordinary legal fiction created by humanity. In today's world, it is rare for any human being not to live under its aegis. It happens that, as from the beginning of the organization of political societies, the State has been in constant transformation, arising from the updating of the social contract. Such transformations accelerate considerably in times of crisis, as is the case with the COVID-19 pandemic. During this period, the State has carried out aggressive interventions in the economy, seeking to replace economic activity, momentarily paralyzed due to the measures to contain the virus. Thus, proposals that in the recent past were not taken seriously, are finding space to get off the ground. One is Basic Income. The origins of this idea, as well as the guiding principles of it, are fundamental elements for us to understand it. Brazil, despite never having practiced it, since 2004 already has a law dealing with the subject. In the current moment of crisis, the Brazilian State has approved the Basic Emergency Income, which intends to remunerate those individuals whose income has been interrupted by the measures to contain the pandemic and, therefore, has practiced an action very close to the classic Basic Income. Which State will emerge in the post-crisis? Will Basic Income have space in this new social contract? These are questions to be answered in this work. What we can conclude is that, after this revolutionary period for human action, with the profound transformations that occurred in capitalism in this century, there will be a need to update the way in which the State relates to society and the economy and, therefore, sees there is room for the consolidation of the Basic Income policy as a permanent action of the State.
\end{abstract}

Keywords: State; Basic Income; COVID-19; Basic Emergency Income.

\title{
1 Introdução
}

O desenvolvimento do Estado e suas respectivas relações com a sociedade, fundadas em um contrato social que está em constante atualização é tema que não perde contemporaneidade.

Ao final da segunda década do século XXI, a humanidade vive a sua maior calamidade desde a II Guerra Mundial, em razão do acometimento da pandemia da COVID-19. O novo coronavírus possui uma capacidade de proliferação alarmante na transmissão humano-para-humano ${ }^{1}$ e, devido às medidas de isolamento social promovidas

1 HEYMANN, David;SHINDO, Nahoko.COVID-19: what is nextfor publichealth? The Lancet. V.395, fev. 2020, pp. 542-545.Disponívelem:https://www.thelancet.com/action/showPdf?pii=S0140-6736\%2820\%2930374-3 Acesso em: 9 abr. 2020. 
para contê-lo, ocasionou a paralisação quase integral da atividade econômica em todos os continentes do mundo ${ }^{2}$.

$\mathrm{O}$ isolamento social, além do impacto sobre a economia, produz efeitos no comportamento humano, na medida em que, como o próprio nome já revela, busca o afastamento físico de seres humanos (isolamento social), em especial no que tange às aglomeraçóes.

Nesse momento, a intervenção do Estado destinada a subsidiar a economia tem sido decisiva. Muitas propostas que no passado recente eram rechaçadas, hoje encontram ambiente para sua execução. Uma delas é a referente à Renda Básica.

A investigação da inserção dessa proposta em específico nesse cenário extraordinário de necessidade da extrema intervenção do Estado na economia é um dos objetivos deste trabalho. Para tanto, será necessário compreender suas origens, seus conceitos elementares, em quais ideologias encontra trânsito, bem como a experiência brasileira no tema. Posteriormente se ingressará na ação emergencial promovida pelo Estado brasileiro, que é, no mínimo, muito próxima da ideia clássica de Renda Básica.

Também se fará uma reflexão sobre o próximo nível de desenvolvimento do Estado e, nesse sentido, se verificará se a Renda Básica teria espaço para firmar-se definitivamente como uma política pública do século XXI.

A pesquisa busca responder questóes atuais e interessantes para a sociedade e, principalmente, refletir sobre as profundas mudanças que o Estado está sofrendo no século XXI. Tais transformaçóes podem, inclusive, gerar um novo contrato social entre a sociedade que almejará um Estado adaptado ao que de novo inevitavelmente virá.

\section{Estado no século XXI}

A contextualização do tema proposto exige precisar o conceito de Estado Contemporâneo no século XXI. Tal instituição, criada pela humanidade, provém dos primórdios da civilizaçáo, tendo passado por diversas fases de desenvolvimento e maturação, até chegar ao ponto da história onde se encontra e com a concepção da atualidade sobre o Estado.

Bresser-Pereira (2009) lembra que o modelo de Estado do século XXI é produto de um longo processo histórico, iniciado desde a Antiguidade. Até aqui um longo caminho foi percorrido, afinal "O poder social sempre existiu na sociedade humana, apresentando, em qualquer grupo social, traços característicos de sociabilidade - o poder

2 MCKIBBIN, Warwick; FERNANDO, Roshen. The global macroeconomic impacts of COVID-19: seven scenarios. CAMA Working Paper, No 19/2020, mar. 2020. Disponível em: https://papers.ssrn.com/sol3/ papers.cfm?abstract_id=3547729 Acesso em: 9 abr. 2020. 
é um fenômeno social - e de bilateralidade - o poder é a correlação de duas ou mais vontades, sendo que uma predomina." (SOARES, 2001, p. 47).

A definição desse conceito não é uma tarefa fácil, pois, em razão da multiplicidade de fases desenvolvidas nesse estágio evolutivo, encontram-se envolvidos numerosos conflitos nascidos na relação do Estado com a sociedade e sua absorção/superaçáo pela racionalidade do sistema político.

De acordo com Gozzi (2016), pode-se elencar entre tais problemas a dicotomia entre Estado Social e Estado de Direito, já que o primeiro sugere uma intervençáo estatal para a garantia dos direitos sociais, enquanto o segundo busca proteger as chamadas liberdades dos indivíduos. Neste segundo modelo, originado pela separação do Estado da propriedade, gerou-se a dependência fiscal do Estado à sociedade; a questáo da "politicização" da administração que, para esse autor, conflita com a racionalidade weberiana, já que "tem que compor as solicitaçōes do ambiente com a lógica legal-racional do sistema político" (GOZZI, 2016, p. 407).

Bobbio (2019), ao abordar o Estado, ensina que deve ser analisado "em si mesmo, em suas estruturas, funçóes, elementos constitutivos, mecanismos, órgáos etc., como um sistema complexo considerado em si mesmo e nas relaçóes com os demais sistemas contíguos" (BOBBIO, 2019, p. 71).

Ao percorrer a trajetória da formação do Estado, desde os primórdios até a contemporaneidade, invariavelmente encontra-se no constitucionalismo, que determinou os limites dos poderes do Estado, um marco relevante. Ao relacionar o constitucionalismo com a democracia, Godoy (2011) abordou o poder constituinte como sendo a origem da ordem constitucional: "É o poder de fazer a nova Constituição, da qual os poderes constituídos adquirem a sua estrutura. Dessa perspectiva, o poder constituinte instala uma ordem jurídico-constitucional totalmente nova" (GODOY, 2011, p. 15).

Bobbio (2019) aborda a questão, atestando que o governo da lei, onde o princípio do legibus solutus é substituído pela rule of law e a norma positivada na forma de lei, é superior ao governo dos homens. Esse autor lembra que, ao contrário do que muitos pensadores liberais acreditaram, o antigo princípio absolutista não se referia ao fato de o soberano não estar submetido às leis, mas ao fato de que aquelas eram escritas pelo próprio. Nesse caso, não havia leis que disciplinassem seus atos, já que "ninguém pode dar leis a si mesmo" (BOBBIO, 2019, p. 128).

O constitucionalismo gerou regras, oriundas dos constituintes, para possibilitar sua aplicação até mesmo aos governantes, subordinando-os. Eis aqui um importante elemento do Estado Contemporâneo, pois "O Constitucionalismo não cria o conceito formal de Constituição, mas atribui-lhe uma exigência específica de forma (escrita, influência do racionalismo liberal, mas cuja principal exceçáo é a Constituição Inglesa) e, sobretudo, um pressuposto de conteúdo diametralmente oposto ao do estado absoluto, 
adotando valores e princípios que são erigidos como condição essencial à Constituição de um Estado de Direito, dentre os quais se destacam a separação dos Poderes e a Declaração Universal de Direitos.” (MUTA, 2007, p. 7).

Outro elemento fundante do Estado na contemporaneidade foi a mudança de suas relaçôes com a sociedade e com a economia, em comparação com o chamado Estado Moderno. Esse último abordava tais relaçóes de maneira liberal, na lógica do laissez-faire, enquanto, desde o final do século XIX e com mais intensidade no decorrer do século $\mathrm{XX}$, o Estado Contemporâneo buscou uma intervenção ativa na economia, o que gerou o chamado Estado Social, em detrimento do Estado Liberal ${ }^{3}$. A convivência de ambos, muitas vezes de maneira pendular, é uma das grandes questóes dessa etapa da formação do Estado.

A progressão das mudanças de relacionamento entre Estado, economia e sociedade foram expostas por Bresser-Pereira (2009), ao afirmar que o Estado contemporâneo passa pela fase social-liberal republicana. Este Estado é concebido pelo autor em razão de seu compromisso com a justiça social e, ao mesmo tempo, com o livre-mercado (socialliberal), além de atentar ao controle social do uso do recurso público e à entrega de eficientes serviços sociais e científicos à população (republicano). A linha do tempo da formação do Estado na visão bressereana é assim exposta:

Ele começou como autoritário e patrimonial nos séculos XVI e XVII: era o Estado absoluto organizando monarquias patrimoniais. No século XIX, tornou-se liberal e burocrático: o Estado liberal impôs o estado de direito e garantiu os direitos civis, ou seja, os direitos à vida, à liberdade e à propriedade privada, mas permaneceu autoritário, pois os pobres e as mulheres não votavam. Na primeira parte do século XX, a transição para a democracia estava completada: foi a época do Estado liberal, da democracia elitista ou liberal e, ainda, da administração burocrática. Na segunda parte desse século, o Estado se tornou socialdemocrático, protegendo os direitos sociais e promovendo o desenvolvimento econômico; a administração continuou sendo burocrática, mas assumiu um caráter desenvolvimentista; a democracia passou a ser social ou plural, mais do que simplesmente liberal. No início do século XXI, o Estado almeja se tornar socialliberal e republicano; a democracia almeja se tornar participativa ou republicana; e a administração almeja se tornar gerencial, ou inspirada nos princípios da nova gestáo pública. (BRESSER-PEREIRA, 2009, n.p.).

Adicione-se ao conjunto de elementos fundantes do Estado Contemporâneo a democracia ou a participação da população de forma direta e indireta nas ações do Estado. Não é escopo deste estudo explorar o tema em profundidade, mas não se pode deixar de registrar o conceito de "democracia republicana" bresseriano, que servirá para contextualizar a democracia nesse estágio de desenvolvimento do Estado.

Basicamente, o autor entende que o processo de controle social, sufrágio universal e debate público - esse último precedendo as decisões tomadas por representantes formais 
da população -, caracterizam o que chamou de democracia republicana, um elemento fundamental do Estado no século XXI e igualmente oriunda de um longo processo político-social evolutivo. Destarte, o Estado social-liberal republicano também será democrático, na medida em que contará com instrumentos de participação deliberativa da sociedade ${ }^{4}$.

\section{Origens da proposta de renda básica}

Em seu livro Utopia, Thomas More teve o ineditismo de apresentar brevemente ao mundo uma ideia simples, mas polêmica: pagar uma renda básica a todas as pessoas. Tal feito se deu na seguinte passagem de sua obra:

Impóem-se ao roubo puniçóes brutais e arrepiantes, quando seria muito mais sensato assegurar que as pessoas tivessem meios de subsistência, e ninguém enfrentaria a terrível necessidade de roubar primeiro e depois morrer por causa disso'. (MORE, 2018, n.p.).

Em que pese o ineditismo de More, foi Thomas Paine o pensador que esmiuçou a ideia do pagamento de uma renda básica a todos os cidadãos, independente de sua renda pessoal ou familiar. A vida desse pensador, que participou da independência norteamericana e da Revolução Francesa, está intimamente ligada à propagação de ideias revolucionárias e, nesse sentido, da proposta de renda básica universal.

O pensamento de Paine, influente até hoje na ciência política e em áreas correlatas, navegou a linguagem dos interesses, do direito natural e do contratualismo 5 .

Ao escrever sua obra Justiça Agrária, Paine expôs o argumento de que, como preconizava o direito natural, a terra não possuía proprietários privados. Ou seja, a terra era de todos, que organizavam as atividades produtivas para dela tirar o sustento da coletividade. Com o tempo, os homens foram se apropriando desse patrimônio da humanidade e, assim, privatizaram aquilo que sempre foi público. Ao fazê-lo, o homem dedicou-se a obter proventos da terra e utilizar-se deles para a acumulação de riqueza.

Esse comportamento, para Paine, gerou a pobreza, criação desse modo de vida "civilizado", baseado na propriedade privada. A pobreza não existia no estado natural, ao mesmo tempo que os benefícios vindos da agricultura, das artes, das ciências e da manufatura só são possíveis devido ao estado civilizado. O seguinte trecho de sua obra explicita o pensamento abordado acima:

A vida de um indígena é um feriado contínuo se comparada com a de um pobre na Europa; e, em contraste, revela-se abjeta se comparada com a de um rico. Portanto, a civilização, ou como queiramos chamá-la, opera em dois sentidos: tornando uma parte da sociedade mais opulenta, e outra mais miserável, do que ambas teriam sido no estado

4 BRESSER-PEREIRA, Luiz Carlos. Construindo o Estado republicano: democracia e reforma da gestão pública. Rio de Janeiro: Fundação Getúlio Vargas, 2009, n.p.

5 CARVAlHO, Daniel Gomes de. Thomas Paine: artífice e obra da era das revoluçóes. In: PAINE, Thomas. Justiça Agrária. Jundiaí: Paco Editorial, 2019, n.p. 
de natureza. É sempre possível passar do estado de natureza para o estado de civilização, mas é impossível ir do estado de civilização ao estado de natureza. A razão reside no fato de que o homem natural, subsistindo por meio da caça, necessita de uma quantidade dez vezes maior de terra sob seu alcance para garantir seu sustento do que necessita em um estado de civilização, no qual há o cultivo de terra. (PAINE, 2019, n.p.)

Ou seja, o autor apontava a desigualdade social oriunda do capitalismo (ainda em uma forma inicial) que propiciava acumulação de renda para alguns e pobreza para outros tantos. E entendia que o sustento de todos os indivíduos seria impossível no estado natural, sem a agricultura organizada para as colheitas férteis e em escala.

Desta forma, Paine entendia que, no que tange aos produtos colhidos na terra, por terem sido cultivados pela empresa privada, seriam de propriedade privada do produtor, mas, por ser um patrimônio público, a terra deveria ser tributada e tais riquezas reunidas em um fundo. "O Criador nunca abriu um cartório de registros de terras, a partir do qual os primeiros títulos de propriedade foram emitidos. Por que motivo, entáo, originou-se o conceito de propriedade de terras?" (PAINE, 2019, n.p.).

Da mesma forma que questionava a propriedade privada e entendia ser justo um tributo sobre a terra, Paine também estendeu seus questionamentos à herança. Ora, se no estado natural a terra não tem proprietários privados, muito menos a mesma poderia ser transmitida hereditariamente pelo motivo da morte do "proprietário". Nesse sentido, seria essencial "que o monopólio da herança natural, que nunca foi um direito, comece a ter um fim" (PAINE, 2019, n.p.).

Aqui, o que Paine na verdade propunha era a instituição um imposto sobre herança de terras, a ser adicionado ao fundo que objetivava pagar uma renda básica a todos. Ressalte-se que o pensamento de Paine náo conflitava com a existência da propriedade privada, mas buscava solucionar sua permanência com a desigualdade social gerada pelo acúmulo capitalista. Preservava o fundamento do capitalismo, a produção gerada pela propriedade privada, mas, por outro lado, entendia como justa uma tributaçáo progressiva sobre quem possuía mais para auxiliar quem possuía menos e, para isso, fundamentava-se em um raciocínio oriundo do jusnaturalismo.

Então, Paine discorreu sobre a ideia da Renda Básica Universal, a ser paga através dos financiamentos já elencados acima a todos os cidadãos, sem observação da renda de cada um: "Propóe-se que os pagamentos, como já se disse, sejam feitos a todos, ricos ou pobres. É melhor fazê-los para evitar qualquer distinção entre os indivíduos" (PAINE, 2019, n.p.).

Basicamente, o autor defendeu, em 1797, o pagamento de uma renda a todos os cidadãos a partir de seus 21 anos de idade, a título do direito que todos, em tese, possuiriam da herança natural da terra a qual, "justamente por ser um direito, pertence a qualquer homem, a despeito da propriedade que ele possa ter adquirido ou herdado" (PAINE, 2019, n.p.). 


\section{Definiçáo de renda básica}

Para que possamos compreender o conceito em foco, deve-se estudar os elementos constitutivos da Renda Básica e seus significados como um programa a ser executado pelo Estado.

Inicialmente é importante conceituar o que seria uma renda "básica", ou seja: o que seria o básico para um ser humano ter uma vida digna? Uma renda que propicie o acesso à alimentação, moradia, educação e saúde seria, logicamente, um bom ponto de partida. Mas há muitos debates sobre o tema.

Nesta difícil busca pela definição do conceito de uma renda básica, há o entendimento de que "a renda básica sustenta a ideia de um dever inalienável que proporciona para cada indivíduo o direito de equilibrar a sua vida em liberdade, propagando a sustentabilidade da sociedade" (CUNHA; POSSAMAI; MAY, 2019, p. 53).

Em uma visão liberal, também existem pensadores que defendem uma renda mais alta possível de ser paga e muito acima da linha da pobreza, com a condicionante de que todos os demais serviços sociais prestados pelo Estado sejam substituídos por tal renda ${ }^{6}$.

Enquanto "renda", Van Parijs (2000) lembra que "é paga em dinheiro, e não na forma de bens ou serviços" e, também, "de maneira regular e não como uma doação única” (VAN PARIJS, 2000, p. 180), buscando diferenciar a Renda Básica de outros programas de transferência de renda eventualmente existentes.

Mormente, o conceito de "básico" teria espaço para outras tantas definiçóes, sempre relacionadas à realidade social da localidade a ser implementada, bem como à condiçãao fiscal do Estado em questão.

Já o termo "universal", ao contrário da difícil definiçãao do conceito de "básico", encontra consenso na literatura a respeito, já que, flagrantemente, objetiva remunerar todos os indivíduos de uma sociedade, independente da renda já obtida por indivíduos através de outros meios. O que, em verdade, não se encontra é consenso na universalidade em si, ou seja, se a renda básica deveria paga a todos os nacionais ou para alguns recortes sociais, mesmo porque entram nesse debate os imigrantes e os cidadãos não-natos, tal como destaca a definição de Standing:

En un mundo ideal nos gustaría que cada ser humano fuese capaz de tener una igual seguridad básica en los ingresos. Pero aquí «universal» significa que una renta básica sería pagada a cada residente habitual de una comunidad, provincia o país dados. La renta básica no sería, estrictamente hablando, un «ingreso ciudadano», como es designada a veces, porque los ciudadanos no residentes no cumplirían los requisitos para recibirla. A la inversa, a los inmigrantes se les podría requerir que fuesen residentes legales por un tiempo definido (o, en el caso de los extranjeros, haber alcanzado un estatus de

6 STANDING, Guy. La renta básica. Barcelona: Pasado e Presente, 2018, p.14. 
residencia permanente) antes de cumplir los requisitos para recibir la renta básica. Esto es un problema político que debe ser resuelto democráticamente. (STANDING, 2018, p. $14-15)$.

O termo "universal", aliás, nem mesmo é utilizado por alguns autores, já que, como "renda básica", entendem nele estar implícita a amplitude universal do programa:

Basic Income is an income paid by the state to each full member or accredited resident of a society, regardless of whether he or she wishes to engage in paid employment, or is rich or poor or, in other words, independently of any other sources of income that person might have, and irrespective of cohabitation arrangements in the domestic sphere. (RAVENTÓS, 2007, p. 8).

Note-se que a ideia de transferir renda para todos os indivíduos de uma sociedade não inclui as tradicionais condicionantes de contraprestaçáo de qualquer exigência para tanto, o que está incluso no termo "universal":

Unlike means-tested subsidies that depend on defined levels of poverty or types of situation, Basic Income is received work or the willingness to accept a job if offered. (as the definition suggests), that excludes any additional condition. Like the right of universal suffrage, the Basic Income proposal does not impose any conditions beyond citizenship (or accredited residence). (RAVENTÓS, 2007, pp. 9 - 10).

A desnecessidade de condicionantes para a percepção da renda básica por todos também é compartilhada por Van Parijs (1992, p. 3) como "an income unconditionally paid to all on an individual basis, without means test or work requirement".

Ele defende que a Renda Básica “é uma renda paga por uma comunidade política a todos os seus membros individualmente, independentemente de sua situação financeira ou exigência de trabalho" (VAN PARIJS, 2000, p. 179).

Aqui se destaca o conceito de "incondicionalidade", ou seja, a Renda Básica será paga incondicionalmente a todos os indivíduos, independente de quem sejam ou de quanto ganhem, bem como do que eles venham a fazer com o emprego de tal recurso. Widerquist, Vanderborght, Noguera, et al. (2013) concordam com o autor, frisando a questão da universalidade e também da incondicionalidade:

Contrary to existing minimum income schemes, Basic Income is both universal and unconditional. It is universal in the sense that it is paid to every citizen or every resident. It is not a categorical benefit, which is only paid to certain individuals who fit specific criteria of eligibility. It is unconditional in the sense that recipients are not required to perform any duties in return for their benefit other than to maintain their membership in the political community. It is paid regardless of whether the recipient is working, willing to work, or has a work record. As a universal, unconditional benefit, it is paid regardless of whether the recipient has other sources of income and irrespective of disposable income. It is paid regardless of whether the recipient is young or old, able or disabled. (WIDERQUIST; VANDERBORGHT; NOGUERA, et al., 2013, p. 6-7).

Standing (2018) sustenta que uma renda básica deveria ser paga de maneira gradual, incrementando o provento na medida do tempo e jamais visando substituir 
os elementos constitutivos do Estado de Bem-Estar Social, ou seja, sem a extinção dos demais serviços públicos prestados pelo Estado.

Widerquist, Vanderborght, Noguera e outros (2013) lembram que há várias formas de expressar a açáo do Estado em remunerar todos os cidadãos universal e incondicionalmente: Renda Garantida, Renda Anual Garantida, Renda Básica Incondicional, Renda Cidadã, Dividendo Social, Concessão Universal e muitas outras. Suplicy (2007, 2003, 1995) também classificou como Renda Básica de Cidadania e Renda Mínima. Nesse trabalho, serão utilizadas as expressōes Renda Básica Universal ou Renda Básica, pois têm sentido mais corrente.

\section{Renda básica: esquerda ou direita?}

Ao longo da história, a Renda Básica tem sido defendida tanto por autores de esquerda quanto por liberais de direita. Tal amplitude ideológica tem registros em escritos dos mais diversos intelectuais, em diferentes épocas, conforme se verá adiante.

O pensamento de Paine influenciou outros teóricos de sua época, no início do século XIX, tais como Thomas Spence, na Inglaterra; Charles Fourier, na França; e Joseph Charlier, na Bélgica. Esses autores entendiam que seria necessário leiloar os imóveis (Spence) ou estatizar os imóveis privados e cobrar uma taxa por seu uso (Fourier) para subsidiar uma renda básica aos cidadãos ${ }^{7}$.

Da mesma forma, Bertrand Russell, em 1918, defendeu que uma "certa renda, suficiente para as necessidades, sera冈 garantida a todos, quer trabalhem ou não" (RUSSELL apud SUPLICY e BUARQUE, 1997, p. 82).

De linha intervencionista, Anthony Atkinson (2013) elaborou uma proposta que chamou de Renda de Participação (Participation Income) que seria uma primeira fase rumo ao que chama de Renda de Cidadania (Citzen's Income). Neste caso, o Estado faria uma série de alteraçóes no regramento tributário e previdenciário (fim do subsídio e de algumas faixas de isenção no imposto de renda, taxação de benefícios sociais e fim do teto de contribuição previdenciário) para o pagamento de uma renda básica a todas as crianças e uma renda de participação a todos os maiores de 18 anos, essa última entendida como um complemento de renda de acordo com a condição social do cidadáo.

Entre os liberais, Milton Friedman (1968) também, ao seu modo, defendeu uma espécie de Renda Básica, denominada Renda Mínima Garantida (Guaranteed Minimum Income), e nesta hipótese o Estado seria responsável por compor a renda daquelas famílias que não atingissem um ordenado mínimo. Friedman apresentou seu argumento no contexto de um Imposto de Renda Negativo (Negative Income Tax), instituindo um

7 SILVA, Robson Roberto da. Renda mínima e proteção social: aspectos históricos, teóricos e conjunturais. Revista Katálysis, v. 22, n. 1, Florianópolis, jan. - abr. 2019, p. 112. 
limiar de renda em que as pessoas que percebessem acima do mesmo pagariam impostos e aquelas que percebessem abaixo dele receberiam um complemento do Estado $^{8}$.

Prosseguindo na ideia, Friedman (1994) exemplificou a importância da disponibilidade monetária através da teoria do helicopter Money. O autor faz o exercício imaginativo de um helicóptero jogando dinheiro sobre uma comunidade, buscando demonstrar que, em uma situação de baixa liquidez no mercado, simplesmente distribuir dinheiro às pessoas na forma de transferência direta de renda ou de corte de impostos seria uma alternativa para o reaquecimento da atividade econômica:

Let us suppose, then, that one day a helicopter flies over our hypothetical long-stationary community and drops additional money from the sky equal to the amount already in circulation - say, $\$ 2,000$ per representative individual who earns $\$ 20,000$ a year in income. The money will, of course, be hastily collected by members of the community. Let us suppose further that everyone is convinced that this is a unique event which will never be repeated. (FRIEDMAN, 1994, p. 29)

Hayek, outro liberal de grande expressão histórica e teórica, concorda com a necessidade de um Renda Básica: "mas não há dúvida de que, no tocante a alimentação, roupas e habitação, é possível garantir a todos um mínimo suficiente para conservar a saúde e a capacidade de trabalho" (HAYEK, 2010, p.128).

Na contemporaneidade, Bregman (2017) tem sido um difusor dessa tese:

Uma renta básica universal. Y no simplemente durante unos años, o solo em los países desarrollados, o sólo para los pobres, sino estrictamente lo que se lee em la etiqueta: dinero grátis para todos. No como um favor, sino como um derecho. Podemos llamarlo el "caminho capitalista hacia el comunismo". Uma paga mensual, lo suficiente para vivir, sin tener que levantar um dedo. La única condición es "tener pulso". Sin inspectores que nos vigilen por encima del hombro para ver si lo hemos gastado com sensatez, sin nadie que custione si verdade nos lo merecemos. No más programas de assistência y ajuda especial; a lo sumo uma paga adicional para los mayores, los desempleados y los incapacitados para trabajar. La hora de la renta básica há llegado. (BREGMAN, 2017, p. 40).

A norte-americana Annie Lowrey (2018) também a defende e encontra na mesma elementos morais diferenciados:

A UBI is an ethos as much as it is a technocratic policy proposal. It contains within it the principles of universality, unconditionality, inclusion, and simplicity, and it insists that every person is deserving of participation in the economy, freedom of choice, and a life without deprivation. (LOWREY, 2018, p. 11)

No Brasil, o ex-senador da República Eduardo Suplicy é um dos maiores defensores da proposta e defende que a ideia - a qual denomina Renda Básica de Cidadania possibilitaria a todos os brasileiros a participação na riqueza da nação?

8 FRIEDMAN, Milton. The case for a negative income tax: a view from the right. In: BUNZEL, John. Issues in American Public Policy. Nova Jersey: Prentice-Hall, 1968, pp. 111-120.

9 SUPLICY, Eduardo. O direito de participar da riqueza da nação: do programa Bolsa Família à Renda Básica 
Também no país, Pierdoná, Leitão e Furtado Filho (2019, p. 396) incluem-se entre os defensores da Renda Básica, argumentando que "a perspectiva social da igualdade não pode ser considerada um dos núcleos principiológicos do ordenamento jurídico”, já que o Estado há que respeitar as diversidades étnicas, culturais, intelectuais, etc, dos indivíduos, o que gera um ambiente diverso e democrático. E seguem:

Sendo mais claro: de fato, a redução das desigualdades é um dos objetivos da República; porém, a realização desse objetivo depende de políticas públicas que não visem diretamente à redução das desigualdades. Ao invés disso, a melhor estratégia é implementar medidas de valorização da condição humana. A redução das desigualdades é uma consequência, um resultado. (PIERDONÁ; LEITÃO; FURTADO FILHO, 2019, p. 396)

Esses autores utilizam a teoria econômica do segundo melhor (second best), que preconiza a utilizaçáo da segunda opçáo mais vantajosa na impossibilidade do uso da primeira. Ou seja, na impossibilidade de atingirmos o princípio da igualdade plena (first best), que se utilize o princípio da diferença para reduzir a desigualdade entre os indivíduos.

Prosseguem defendendo como critérios de elegibilidade para a Renda Básica possuir nacionalidade brasileira, registro no Cadastro de Pessoa Física (CPF) e residir no território nacional. Ou seja, os princípios da incondicionalidade e da universalidade.

É possível continuar elencando outros tantos autores, com diferentes visões de mundo, para ilustrar a amplitude ideológica da proposta de Renda Básica, tamanha é a proliferação da literatura sobre o tema, oriunda dos mais diversos autores. Tal observaçáo se faz importante, pois não se trata de uma ideia necessariamente limitada a alguma linha ideológica, mas sim de uma forma de relacionamento entre o Estado e a sociedade que encontra acolhimento em qualquer ideologia, sendo referida por alguns teóricos como princípio da precaução, que "implica a necessidade de um diálogo contínuo entre sociedade civil, instituiçôes e empresas, na procura de opçóes praticáveis que permitam uma contemporização mais eficaz e comumente aceita dos benefícios e dos riscos decorrentes do desenvolvimento científico." (BARBARO, 2013, p. 181)

\section{Proposta de renda básica no Brasil: Lei 10.835/04}

No âmbito do Estado brasileiro, o tema da Renda Básica tem sido debatido pelo menos desde a década de 1990 no Congresso Nacional, com a apresentação do projeto de lei, em 1991, que culminou com a sanção da Lei 10.835, de 8 de janeiro de $2004^{10}$.

de Cidadania. Ciênc. saúde coletiva, Rio de Janeiro , v. 12, n. 6, p. 1623-1628, Dec. 2007. Disponível em: <http://www.scielo.br/scielo.php?script=sci_arttext\&pid=S1413-81232007000600023\&lng=en\&nrm $=$ iso $>$. Acesso em 8 abr. 2020.

10 CUNHA, Amanda Rutineia; POSSAMAI, Angélica Pereira; MAY, Yduan de Oliveira. Renda básica de cidadania, definida na lei nr 10.835/2004: desafios e oportunidades para a inclusão sócio-econômica. In: GIANEZINI, Kelly; RODRIGUES, Adriane Bandeira. Políticas públicas no século XXI. Criciúma: UNESC, 2019. p. 56. 
Logo no primeiro artigo desse diploma legal já se verifica o objetivo do legislador em instalar a Renda Básica no Brasil:

Art. 1: É instituída, a partir de 2005, a renda básica de cidadania, que se constituirá no direito de todos os brasileiros residentes no País e estrangeiros residentes há pelo menos 5 (cinco) anos no Brasil, não importando sua condição socioeconômica, receberem, anualmente, um benefício monetário. (BRASIL, 2004)

Em que pese o nome dado ao benefício ser "renda básica de cidadania", verifica-se tratar-se da mesma Renda Básica já referida neste trabalho, pois, de acordo com o exposto no referido artigo, nela se encontram os princípios da universalidade, individualidade, periodicidade e incondicionalidade.

Os parágrafos do mesmo artigo determinam um caráter de implementação progressivo, com prioridades à população mais pobre (10); fixam o princípio de isonomia nos valores dos pagamentos, exigindo seja "suficiente para atender às despesas mínimas de cada pessoa com alimentação, educação e saúde" (BRASIL, 2004) com a ressalva da capacidade orçamentária do país $\left(2^{\circ}\right)$; abrem a possibilidade para a periodicidade mensal do pagamento do benefício (30); e isentam da tributação do imposto de renda (4o).

$\mathrm{O}$ artigo $2^{\circ}$ faz constar que o valor do benefício será definido pelo Poder Executivo, observando a legislação de responsabilidade fiscal brasileira. $\mathrm{O}$ próximo artigo trata da necessidade de inclusão no Orçamento Geral da União (OGU) do ano seguinte das despesas necessárias para a implementação da primeira fase do programa e, por fim, o artigo $4^{\circ}$ remete à necessidade da inclusão, nos anos subsequentes, das despesas previstas para a execuçáo do programa nos planos plurianuais e também nas leis de diretrizes orçamentárias.

Até o presente momento, apesar da lei estar sancionada desde 2004, o Poder Executivo ainda não editou os regulamentos imprescindíveis à sua plena aplicação, permanecendo, portanto, inaplicável. Dois principais fatores são apontados para que isso ocorra: a) há uma competição com o programa Bolsa Família, consolidado no país e b) as condicionantes do programa à capacidade orçamentária impedem a execução do mesmo ${ }^{11}$.

Apesar da probabilidade dessa proposta ser mais uma das tantas que viraram lei e foram fadadas ao esquecimento, algo inusitado aconteceu e alterou todo esse panorama: a pandemia da COVID-19.

11 PIERDONÁ, Zélia Luiza; LEITÃO, André Studart; FURTADO FILHO, Emmanuel Teófilo. Primeiro, o básico. Depois, o resto: o direito à renda básica. Revista Jurídica. vol. 02, nº 55, Curitiba, 2019. p. 408. 


\section{Implementação emergencial da renda básica no Brasil: Lei 13.982/20}

No dia 2 de abril de 2020, em meio à pandemia da COVID-19 que aterroriza o mundo e se tornou uma das maiores calamidades sanitárias e econômicas da história recente da humanidade ${ }^{12}$, o presidente da República, Jair Bolsonaro, sancionou a Lei 13.982, que alterou os parâmetros sociais para recebimento do Benefício de Prestaçáo Continuada (BPC) e estabeleceu "medidas excepcionais de proteção social a serem adotadas durante o período de enfrentamento da emergência de saúde pública de importância internacional decorrente do coronavírus (Covid-19) responsável pelo surto de 2019” (BRASIL, 2020).

Há nesse diploma, de maneira inédita no país, a implantação de algo muito próximo daquilo que se denomina Renda Básica, já que o Estado brasileiro pagará um certo valor, por um período determinado de tempo a todos os indivíduos que se enquadrarem em alguns critérios sociais, como segue abaixo:

Art. $2^{\circ}$ Durante o período de 3 (três) meses, a contar da publicação desta Lei, será concedido auxílio emergencial no valor de $\mathrm{R} \$ 600,00$ (seiscentos reais) mensais ao trabalhador que cumpra cumulativamente os seguintes requisitos:

I - seja maior de 18 (dezoito) anos de idade;

II - não tenha emprego formal ativo;

III - não seja titular de benefício previdenciário ou assistencial ou beneficiário do segurodesemprego ou de programa de transferência de renda federal, ressalvado, nos termos dos $\$ \$ 1^{\circ}$ e 2º o Bolsa Família;

IV - cuja renda familiar mensal per capita seja de até 1/2 (meio) salário-mínimo ou a renda familiar mensal total seja de até 3 (três) salários mínimos;

V - que, no ano de 2018, não tenha recebido rendimentos tributáveis acima de R\$ 28.559,70 (vinte e oito mil, quinhentos e cinquenta e nove reais e setenta centavos); e

VI - que exerça atividade na condição de:

a) microempreendedor individual (MEI);

b) contribuinte individual do Regime Geral de Previdência Social que contribua na forma do caput ou do inciso I do $\$ 2^{\circ}$ do art. 21 da Lei no 8.212 , de 24 de julho de 1991; ou

c) trabalhador informal, seja empregado, autônomo ou desempregado, de qualquer natureza, inclusive o intermitente inativo, inscrito no Cadastro Único para Programas Sociais do Governo Federal (CadÚnico) até 20 de março de 2020, ou que, nos termos de autodeclaraçáo, cumpra o requisito do inciso IV.

$\S 1^{\circ} \mathrm{O}$ recebimento do auxílio emergencial está limitado a 2 (dois) membros da mesma família.

12 CONTI, Thomas. Crise Tripla do Covid-19: um olhar econômico sobre as políticas públicas de combate à pandemia. Disponível em: http://thomasvconti.com.br/wp-content/uploads/2020/04/Conti-Thomas-V.2020-04-06.-Crise-Tripla-do-Covid-19-olhar-econômico-sobre-as-pol\%C3\%ADticas-públicas-de-combate-àpandemia.-Texto-para-discussão.-Versão-1.1.pdf Acesso em: 8 abr. 2020. 
$\S 2^{\circ} \mathrm{O}$ auxílio emergencial substituirá o benefício do Bolsa Família nas situaçóes em que for mais vantajoso, de ofício.

$\S 3^{\circ}$ A mulher provedora de família monoparental receberá 2 (duas) cotas do auxílio.

$\S 4^{\circ}$ As condiçóes de renda familiar mensal per capita e total de que trata o caput serão verificadas por meio do CadÚnico, para os trabalhadores inscritos, e por meio de autodeclaração, para os não inscritos, por meio de plataforma digital.

$\S 5^{\circ}$ São considerados empregados formais, para efeitos deste artigo, os empregados com contrato de trabalho formalizado nos termos da Consolidação das Leis do Trabalho (CLT) e todos os agentes públicos, independentemente da relação jurídica, inclusive os ocupantes de cargo ou função temporários ou de cargo em comissão de livre nomeaçáo e exoneraçáo e os titulares de mandato eletivo.

$\S 6^{\circ}$ A renda familiar é a soma dos rendimentos brutos auferidos por todos os membros da unidade nuclear composta por um ou mais indivíduos, eventualmente ampliada por outros indivíduos que contribuam para o rendimento ou que tenham suas despesas atendidas por aquela unidade familiar, todos moradores em um mesmo domicílio.

$\S 7$ Náo seráo incluídos no cálculo da renda familiar mensal, para efeitos deste artigo, os rendimentos percebidos de programas de transferência de renda federal previstos na Lei no 10.836, de 9 de janeiro de 2004, e em seu regulamento.

$\S 8^{\circ}$ A renda familiar per capita é a razão entre a renda familiar mensal e o total de indivíduos na família.

$\S 9^{\circ} \mathrm{O}$ auxílio emergencial será operacionalizado e pago, em 3 (três) prestaçôes mensais, por instituiçóes financeiras públicas federais, que ficam autorizadas a realizar o seu pagamento por meio de conta do tipo poupança social digital, de abertura automática em nome dos beneficiários, a qual possuirá as seguintes características:

I - dispensa da apresentação de documentos;

II - isenção de cobrança de tarifas de manutenção, observada a regulamentação específica estabelecida pelo Conselho Monetário Nacional;

III - ao menos 1 (uma) transferência eletrônica de valores ao mês, sem custos, para conta bancária mantida em qualquer instituição financeira habilitada a operar pelo Banco Central do Brasil;

IV - (VETADO); e

V - não passível de emissão de cartáo físico, cheques ou ordens de pagamento para sua movimentação.

$\S 10$. (VETADO).

$\S 11$. Os órgãos federais disponibilizarão as informações necessárias à verificação dos requisitos para concessáo do auxílio emergencial, constantes das bases de dados de que sejam detentores.

$\S 12$. O Poder Executivo regulamentará o auxílio emergencial de que trata este artigo. (BRASIL, 2020).

Como se vê, a medida, que ficou conhecida como "renda básica emergencial" (RBE), não atende os requisitos de uma Renda Básica tal qual definida neste estudo, pois não cumpre o preconizado pelos princípios da universalidade e incondicionalidade. Além 
de prever o pagamento do benefício por três meses, como estabelece o caput do artigo 2o . O que já foi prorrogado, também em caráter de excepcionalidade.

Porém, há autores que veem nessa ação uma possibilidade real de trilhar o caminho da Renda Básica Universal propriamente dita. A economista brasileira Monica De Bolle (2020), por exemplo, entende que a RBE “é o começo de um caminho já definido pelas características da epidemia”, apontando para uma grande possibilidade de mudança de rumos da relaçáo do Estado com a sociedade. Para essa autora, ao menos os 77 milhões de brasileiros constantes no Cadastro Único do Governo Federal deveriam receber tal benefício permanentemente no futuro, o que, segundo ela, custaria algo em torno de $7 \%$ do PIB nacional ${ }^{13}$.

\section{Consideraçóes finais}

Inicialmente, salienta-se que, ao que tudo indica, passa-se pelo limiar de um novo tempo onde, ao fim, será concebida uma nova forma de Estado. Essa instituição milenar, forjada pela humanidade desde a Antiguidade, se mostra ainda em formação, em desenvolvimento, em maturação e, talvez, em definitiva superação.

Hobbes (2014) formulou a teoria do Estado leviatânico, que seria formado por todos os homens em busca da criação de uma entidade que regulasse a vida em sociedade e os retirasse estado de natureza, onde entáo viveriam permanentemente em conflito ${ }^{14}$.

Ora, seguindo essa linha de pensamento hobbesiano, se o Estado é "formado" por todos os homens, é razoável supor que sofrerá transformações na medida que elas acontecerem e impactarem os próprios homens, elementos constitutivos dessa entidade. Ou seja, mudando a sociedade, mudará o Estado.

Assim sendo, o Estado do século XXI também está em constante aperfeiçoamento e desenvolvimento. Em uma época de calamidade, como é o caso da pandemia causada pela COVID-19, aquelas propostas, antes consideradas inatingíveis e utópicas pela maior parte da sociedade, surgem como grandes soluçóes para os problemas da contemporaneidade.

Nesse contexto, é importante registrar que, assim como o Estado, o sistema econômico vigente no mundo - o capitalismo - também está sofrendo alterações, como argumentou o norte-americano Jeremy Rifkin:

O capitalismo está dando à luz uma descendência. Chama-se economia do compartilhamento. Esse é o primeiro novo sistema econômico a entrar no palco mundial desde o advento do capitalismo e do socialismo no início do século XIX, tornandose um evento histórico notável. A economia do compartilhamento já está mudando o modo como organizamos nossa vida econômica, oferecendo a possibilidade de reduzir

13 DE BOLLE, Monica. Renda básica. Estado de Sáo Paulo, São Paulo, 8 abr. 2020. Disponível em: https:// economia.estadao.com.br/noticias/geral,renda-basica,70003264286 Acesso em: 8 abr. 2020.

14 HOBBES, Thomas. Leviatá: ou matéria, forma e poder de um Estado eclesiástico e civil. São Paulo: Martin Claret, 2014. 
drasticamente a divisão de renda, democratizar a economia global e criar uma sociedade mais ecologicamente sustentável. (RIFKIN, 2016, p. 13)

Concordando com Rifkin, o britânico Paul Mason (2017) chamou essa nova etapa de "pós-capitalismo", onde as mudanças tecnológicas incidirão na sociedade de tal forma que mudarão completamente os hábitos das pessoas e, consequentemente, a economia global. Esse autor entende que há duas hipóteses para o encerramento desse ciclo do capitalismo: a) a elite econômica se sustenta no poder, destinando os ônus do baixo crescimento econômico à classe trabalhadora; b) partidos políticos extremistas tomam o poder dos Estados economicamente centrais e destinam a conta do desaquecimento econômico e da desigualdade social para Estados marginais, gerando conflitos globais ${ }^{15}$.

A crise da COVID-19 pode ter antecipado muitas dessas transformaçōes, suscitando debates que moldarão o comportamento humano do futuro no que se refere à maneira de se relacionar em sociedade e com a sociedade, à forma de trabalhar, lecionar, estudar, etc. Tais alteraçóes de comportamento dos homens certamente incidiráo sobre o Estado, a entidade formada por seu conjunto, como definiu Hobbes.

Conforme já afirmado no presente artigo, a pandemia não causou mais uma crise econômica. Ela impediu de forma quase integral a existência da atividade econômica por um período, mantendo-a em níveis insignificantes, como mostra o relatório de análise econômica da pandemia produzido pelo Estado do Rio Grande do Sul, apontando queda de $43 \%$ de atividade econômica no varejo e na indústria entre 21 e 27 de março de 2020 - semana do início de quarentena nesse Estado brasileiro ${ }^{16}$. Ou seja, não se trata de uma crise econômica como outras tantas pois, ao menos por um período, o Estado deverá simplesmente substituir a atividade econômica, subsidiando a economia e aumentando o deficit público.

A Renda Básica surge nesse cenário. O que antes era uma proposta considerada esteticamente ideal, mas longe de ser concretizada, hoje tornou-se algo vigente no Brasil. Não seria exagero imaginar que, para a humanidade que emergir desse período, essa e outras tantas propostas inovadoras venham a se consolidar tornando-se realidades que buscarão selar um novo pacto entre a sociedade e o Estado.

Desse novo pacto social pode nascer um Estado capaz de solucionar os problemas apresentados na pré-crise, tais como a extinção de milhôes de postos de trabalho, tendo em vista os efeitos das transformaçóes do capitalismo, o aumento das desigualdades sociais e a crise de representatividade política. Na hipótese de se obter uma configuração

15 MASON, Paul. Pós-capitalismo: um guia para o nosso futuro. São Paulo: Companhia das Letras, 2017, n.p. 16 RIO GRANDE DO SUL. Secretaria de Estado da Fazenda. Receita Estadual publica Boletim com análise do impacto do Covid-19 em setores da economia. Porto Alegre, RS. 2020. Disponível em: https://www.fazenda. rs.gov.br/conteudo/12930/receita-estadual-publica-boletim-com-analise-do-impacto-do-covid-19-em-setoresda-economia Acesso em: 9 abr. 2020. 
de pacto social em que a Renda Básica seja adotada, ter-se-á, então, uma nova etapa de desenvolvimento e formação do Estado.

Essa hipotética nova fase do Estado, em que as pessoas receberiam uma renda básica universal, incondicional, periódica e individual, geraria profundas transformações na relaçáo capital-trabalho e incidiria fortemente sobre a desigualdade social. A reconfiguração do Estado haveria de ser completa, pois muitas de suas funçóes tornar-seiam obsoletas ou ultrapassadas. Nesse compasso, ingressar-se-á, então, em uma nova fase de desenvolvimento do Estado, chamado de Estado 2.0.

\section{Referências}

BARBARO, Sergio. Princípio da precauçáo, relação e bem comum. Fraternidade como categoria jurídica, org. PIERRE, Luiz et alli. Cidade Nova. São Paulo, 2013.

BOBBIO, Norberto. Estado, governo e sociedade: fragmentos de um dicionário político. 22. ed. Rio de Janeiro, São Paulo: Paz e Terra, 2019.

BONAVIDES, Paulo. Do Estado social ao Estado liberal. 6. ed. São Paulo: Malheiros, 1996.

BRASIL. Lei n. 10.835, de 8 de janeiro de 2004. Institui a renda básica de cidadania e dá outras providências. Brasília, DF, 2004. Disponível em: http://www.planalto.gov. br/ccivil_03/_Ato2004-2006/2004/Lei/L10.835.htm Acesso em: 8 abr. 2020.

BRASIL. Lei n. 13.982, de 2 de abril de 2020. Altera a Lei no 8.742, de 7 de dezembro de 1993, para dispor sobre parâmetros adicionais de caracterização da situação de vulnerabilidade social para fins de elegibilidade ao benefício de prestação continuada (BPC), e estabelece medidas excepcionais de proteção social a serem adotadas durante o período de enfrentamento da emergência de saúde pública de importância internacional decorrente do coronavírus (Covid-19) responsável pelo surto de 2019, a que se refere a Lei no 13.979, de 6 de fevereiro de 2020. Brasília, DF. Disponível em: http://www.planalto.gov.br/ccivil_03/_ato2019-2022/2020/lei/ L13982.htm Acesso em: 8 abr. 2020.

BREGMAN, Rutger. Utopía para realistas: a favor de la renta básica universal, la semana laboral de 15 horas y um mundo sin fronteras. Barcelona: Salamandra, 2017.

BRESSER-PEREIRA, Luiz Carlos. Construindo o Estado republicano: democracia e reforma da gestão pública. Rio de Janeiro: Fundação Getúlio Vargas, 2009.

CARVALHO, Daniel Gomes de. O pensamento radical de Thomas Paine (17931797): artífice e obra da Revolução Francesa. Tese (doutorado em História). Faculdade de Filosofia, Letras e Ciências Humanas da Universidade de São Paulo, 2018. 
CONTI, Thomas. Crise Tripla do Covid-19: um olhar econômico sobre as políticas públicas de combate à pandemia. Disponível em: http://thomasvconti.com.br/wpcontent/uploads/2020/04/Conti-Thomas-V.-2020-04-06.-Crise-Tripla-do-Covid-19olhar-econômico-sobre-as-pol\%C3\%ADticas-públicas-de-combate-à-pandemia.-Textopara-discussão.-Versão-1.1.pdf Acesso em: 8 abr. 2020.

CUNHA, Amanda Rutineia; POSSAMAI, Angélica Pereira; MAY, Yduan de Oliveira. Renda básica de cidadania, definida na lei nr 10.835/2004: desafios e oportunidades para a inclusão sócio-econômica. In: GIANEZINI, Kelly; RODRIGUES, Adriane Bandeira. Políticas públicas no século XXI. Criciúma: UNESC, 2019. p. 52-74.

DE BOLLE, Monica. Renda básica. Estado de Sáo Paulo, São Paulo, 8 abr. 2020. Disponível em: https://economia.estadao.com.br/noticias/geral,rendabasica,70003264286 Acesso em: 8 abr. 2020.

FRIEDMAN, Milton. The mistery of money. In: FRIEDMAN, Milton. Money mischief: episodes in monetary history. Boston: Mariner Books, 1994, pp. $8-50$.

FRIEDMAN, Milton. The case for a negative income tax: a view from the right. In: BUNZEL, John. Issues in American Public Policy. Nova Jersey: Prentice-Hall, 1968, p. 111-120.

GODOY, Miguel Gualano de. Constitucionalismo e democracia: uma leitura a partir de Carlos Santiago Nino e Roberto Gargarella. Dissertação (mestrado em Direito). Universidade Federal do Paraná. Curitiba, 2011.

GOZZI, Gustavo. Estado Conteporâneo. In: BOBBIO, Norberto; MATTEUCCI, Nicola; PASQUINO, Gianfranco. In: Dicionário de política. 13. ed. Brasília: Universidade de Brasília, 2016.

HAYEK, Friederich. O caminho da servidáo. 6. ed. São Paulo: Instituto Ludwig von Mises Brasil, 2010.

HOBBES, Thomas. Leviatá: ou matéria, forma e poder de um Estado eclesiástico e civil. São Paulo: Martin Claret, 2014.

LÓPEZ, Mario Justo. Manual de derecho politico. 2. ed. Depalma. Buenos Aires, 1994.

LOWREY, Annie. Give people money: how a universal basic income would end poverty, revolutionize work, and remake the world. Nova Iorque: Crow, 2018.

MASON, Paul. Pós-capitalismo: um guia para o nosso futuro. São Paulo: Companhia das Letras, 2017, n.p. 
MCKIBBIN, Warwick; FERNANDO, Roshen. The global macroeconomic impacts of COVID-19: seven scenarios. CAMA Working Paper, No 19/2020, mar. 2020. Disponível em: https://papers.ssrn.com/sol3/papers.cfm?abstract_id=3547729 Acesso em: 9 abr. 2020.

MUTA, Luis Carlos Hiroki. Direito Constitucional. Tomo I. Campus Elsevier, Rio de Janeiro, 2007.

PAINE, Thomas. Justiça Agrária. Jundiaí: Paco Editorial, 2019.

PIERDONÁ, Zélia Luiza; LEITÃO, André Studart; FURTADO FILHO, Emmanuel Teófilo. Primeiro, o básico. Depois, o resto: o direito à renda básica. Revista Jurídica. v. 02, n. 55, Curitiba, 2019. p. $390-417$.

RAVENTÓS, Daniel. Basic income: the material conditions of freedom. Londres: Pluto Press, 2007.

RIFKIN, Jeremy. Sociedade com custo marginal zero. São Paulo: M. Books, 2016.

RIO GRANDE DO SUL. Secretaria de Estado da Fazenda. Receita Estadual publica Boletim com análise do impacto do Covid-19 em setores da economia. Porto Alegre, RS. 2020. Disponível em: https://www.fazenda.rs.gov.br/conteudo/12930/ receita-estadual-publica-boletim-com-analise-do-impacto-do-covid-19-em-setores-daeconomia Acesso em: 9 abr. 2020.

SILVA, Robson Roberto da. Renda mínima e proteção social: aspectos históricos, teóricos e conjunturais. Revista Katálysis, v. 22, n. 1, Florianópolis, jan. - abr. 2019, p. 110-119.

SOARES, Mário Lúcio Quintão. Teoria do estado. Del Rey. Belo Horizonte, 2001.

STANDING, Guy. La renta básica. Barcelona: Pasado e Presente, 2018

SUPLICY, Eduardo Matarazzo; BUARQUE, Cristovam. Garantia de renda mínima para erradicar a pobreza: o debate e a experiência brasileiros. Estudos Avançados, 11 (30). São Paulo, 1997, p. 79 - 93.

SUPLICY, Eduardo. O direito de participar da riqueza da nação: do programa Bolsa Família à Renda Básica de Cidadania. Ciênc. saúde coletiva, Rio de Janeiro, v. 12, n. 6, p. 1623-1628, Dec. 2007. Disponível em: http://www.scielo.br/scielo. php?script=sci_arttext $\&$ pid=S1413-81232007000600023\&lng=en\&nrm=iso. Acesso em: 8 abr. 2020.

VAN PARIJS, Philippe. Competing justifications of Basic Income. In: VAN PARIJS, Philippe. Arguing for Basic Income: ethical foundations for a radical reform. Londres e Nova Iorque: Verso, 1992, p. 3-43. 
VAN PARIJS, Philippe. Renda básica: renda mínima garantida para o século XXI? Estudos Avançados. São Paulo, v. 14, n. 40, p. 179-210, dez. 2000.

Disponível em: http://www.scielo.br/scielo.php?script=sci_arttext\&pid=S0103$40142000000300017 \& \operatorname{lng}=$ en $\& n r m=$ iso. Acesso em 8 abr. 2020

WIDERQUIST, Karl; VANDERBORGHT, Yannick; NOGUERA, José A., et al. The idea of an unconditional income for everyone. In: WIDERQUIST, Karl; VANDERBORGHT, Yannick; NOGUERA, José A., et al. Basic Income: an anthology of contemporary research. West Sussex: Blackwell Publishing, 2013, p. 2-4. 